\title{
Online humour as a community-building cushioning glue
}

\author{
Vittorio Marone, Ph.D. \\ The University of Texas at San Antonio, Texas, United States of America \\ vittorio.marone@utsa.edu
}

\begin{abstract}
This article examines the uses and functions of humour in an online community of gamers and nonprofessional game designers who present and critique user-generated artefacts created with the popular game series LittleBigPlanet. Findings show that participants use humour and "good humour" to achieve a variety of social goals: to veil statements of ability and effort, alleviate negative comments, present user-generated content, attract new players, support other participants, and overall engender a smiling atmosphere that incentives collaboration, peer feedback, and social cohesion. Far from being a trivial ornament, humour emerges as a community building "cushioning glue" that connects, seals, and buffers different gears of computer-mediated interaction, contributing to defining the boundaries and the identity of the analysed online space.
\end{abstract}

Keywords: humour on the Internet; humour in computer-mediated-communication (CMC); discursive functions of humour; online gaming communities; LittleBigPlanet.

\section{Introduction}

\subsection{Defining Humour}

Humour has been studied in different fields and disciplines, such as philosophy, psychology, sociology, anthropology, and linguistics (Dynel 2009). This has engendered a number of theories, definitions, and taxonomies. For example, Berger (2013) identified as many as 45 techniques of humour that encompass, among others, absurdity, exaggeration, literalness, 
repetition, and unmasking. If we consider that several of these techniques can have a reverse form (e.g. exaggeration/understatement) and can be freely combined (Martin 2007; Berger 2013), the variety of forms and discursive functions of humour appears evident. Acknowledging the complexity and broadness of the topic, the operational definition of humour for this study is "any communicative instance which is perceived as humorous" (Martineau, 1972: 114) or that elicits amusement, laughter, or, more broadly, a "social smile" (Ziv, 2010: 11). Specifically, humour is considered in its interactional and conversational dimensions (Dynel 2009; Norrick 2010) as a discursive tool to achieve situated social goals (Tannen 1984; Mulkay 1988; Wyer \& Collins 1992; Boxer \& Cortés-Conde 1997; Long \& Graesser 1998; Norrick 2003; Norrick \& Chiaro 2009).

\subsection{The Social Functions of Humour}

Conveying humour, "getting it," and laughing at it, can reassure both the sender and the receiver of the humorous message, as they discursively construct shared ground for communication. In this sense, the collective use of humour in social environments can be interpreted as "a thread of constitutive laughter," which is "a collaborative process of perpetuating humour through a series of messages that combines features of spontaneous joking with the confirming act of laughter" (Hubler \& Bell, 2003: 280). However, humour and laughter are not necessarily coextensive (Attardo 2003) and the study of context-specific and social uses of humour (Norrick 2003, 2010), or "what people accomplish with humour rather than the form of humour" (Norrick \& Chiaro, 2009: xiv), can help better understand its functions, besides and beyond the elicitation of smiling, laughter, or amusement.

Research shows that humour can foster the development and maintenance of social relationships, ease the sense of uncertainty that arises in human interactions, and overall facilitate communication (Canary et al. 1993; Graham 1995; Hubler \& Bell 2003). The ability to successfully elicit humour in a community is often connected to peer recognition and social desirability, as participants position themselves within the group through conversational discourse (Cann et al. 1997; Martin 1998; Pennington \& Hall 2014). An appropriate use of humour can increase trust and satisfaction among participants, as they experience similarity in social skill levels and knowledge, form shared understandings, and engage in a discursive exploration of affinity (Graham 1995; Kurtzberg et al. 2009), which can narrow social distances between participants (Brown \& Levinson 1978). In a community, humour can alleviate tensions and conflicts (Lefcourt 2001), increase relational intimacy (Baxter 1992), strengthen interpersonal bonds (Martineau 1972), and overall contribute to group well-being and a shared atmosphere of enjoyment (Ziv 2010).

\subsection{Humour in Computer-Mediated Communication (CMC)}

In text-rich online environments, such as discussion forums, blogs, and chats, humorous concepts need to be expressed without the aid of vocal tone, nonverbal gestures, facial expressions, or other visual and auditory cues of humour that are important performance variables in face-toface communication (Garcia \& Jacobs 1999; Hancock 2004a). Overlapping messages or simultaneous feedback, typical of face-to-face interactions, are not practicable (Vandergriff \& 
Fuchs 2012). Further, in several online environments critical interactional variables such as gender, age, or social status (Norrick \& Chiaro 2009) remain unknown, due to the use of nicknames, avatars, or anonymous messages.

Computer-Mediated Communication (CMC) in informal social environments is characterised by loose turn-taking, disrupted turn-adjacency, and a general lack of structure and preparation (Ferrara et al. 1991; Baym 1995; Garcia \& Jacobs 1998; Herring 1999). These factors influence how humour is conveyed and perceived in online social spaces that are not primarily humour-oriented (Shifman 2007), such as the community investigated in this study, making it closer to everyday conversational humour, rather than canned jokes or literary forms of witticism, irony, and satire (Baym 1995).

Research shows that interaction in asynchronous computer-mediated environments, such as discussion forums, can incentive metalinguistic reflection and foster the formation and use of emergent instruments of expression (e.g. emoticons, abbreviations, graphics) that transform the online space into a dynamic stage for creative communication and language play (Ferrara et al. 1991; Danet 2001; Thurlow et al. 2004; Herring 2013). This seems to encourage an extensive use of humour in online social spaces. In this context, Hancock (2004b) found that the participants in an experimental group, who interacted through $\mathrm{CMC}$ in a chat, used more irony to accomplish specific conversational tasks than the participants in the control group, who communicated faceto-face. More broadly, research shows that the use of humour in CMC can help overcome anonymity and reduce the sense of temporal and spatial separation (Baym 1995).

\section{Methods}

In this section I present my positionality statement, I discuss data sources and analyses, and I introduce the methodological approach of the study, rooted in computer-mediated discourse analysis (CMDA) and discourse-oriented ethnography.

\subsection{Positionality Statement}

I position myself within the interpretivist paradigm of research (Angen 2000), which assumes that knowledge and reality are socially and intersubjectively constructed in a situated culture, space, and time. From a constructivist standpoint, I consider myself both an instrument of inquiry and an interpretive link between the object of the research and the reader (Starks \& Brown Trinidad 2007).

As a scholar, I am fascinated by the creative affordances of contemporary digital games that offer powerful, yet accessible game design tools that complement "preset" adventures, transforming players into creators. I define them "playators," calling attention to the role of playful creativity engendered by accessible game design tools, repositioning in a playful-creative realm the constructs of "playbour" (i.e. play and labour; see Kücklich 2005) and "productive play" (Sotamaa 2007) that emphasise the hard, yet unremunerated work of non-professional game designers. For this study, I spent almost three years in the LittleBigPlanet universe, striving to become an insider by playing the titles of the series, connecting with the developers of the game, and reading relevant articles, reviews, and tutorials. 


\section{Computer-Mediated Discourse Analysis and Discourse-Oriented Ethnography}

Computer-mediated discourse (CMD) represents any interpersonal communication carried out through the use of computers, wired and wireless technologies (e.g. Bluetooth, Wi-Fi, and cellular networks), and the Internet (Herring 1996, 2001). Discourse analysis (DA) is a method for investigating written and spoken language in situated sociocultural contexts (Wood \& Kroger 2000; Peräkylä 2005; Gee 2010). Computer-mediated discourse analysis (CMDA) is a methodological framework rooted in sociolinguistic and pragmatic approaches to discourse that brings together these two perspectives and considers language use in computer-mediated settings (Herring 2004). It focuses on the interrelationships between language-in-use (Gee 2010), the communicative affordances of specific technologies (Mazur 2004), and how such affordances mediate and structure the use of language (Herring 2013).

Discourse-Oriented Ethnography is a methodological approach used to investigate the discursive practices and culture of a situated social group (Androutsopoulos 2008; Garcia et al. 2009; Smart 2012). In this approach, the researcher-ethnographer operates as a participantobserver who strives to make sense of the practices and systems of symbols inscribed in the discourse of the community (Geertz 1983).

Given the large number of compliment sequences and other instances of invitations, requests, and complaints found in the analysed discussion forum, other frameworks could have been adopted in the study (e.g. speech acts or politeness theory). However, acknowledging the prominence of the "digital discourse" (Thurlow \& Mroczek 2011) in the investigated textual interactions, a CMDA approach from an ethnographic stance was deemed appropriate to examine cues, uses, and functions of humour in an online space dedicated to gaming and game design.

\section{Data Sources and Analyses}

The corpus of this study consists of 826 posts that represent two continuous months of activity (one in 2008 and one in 2012) of an online discussion forum in which participants present and critique user-generated game levels (i.e. "mini games") designed with the creative tools embedded in the digital games LittleBigPlanet (LBP) and LittleBigPlanet 2 (LBP2) for the PlayStation 3 (PS3) video game console. These titles features a multiplayer mode that allows up to four players to be simultaneously present in the same game level to participate in social adventures or solve specific problems that require a cooperative approach. A distinctive characteristic of this game series is that it allows for the creation of professionally looking usergenerated game levels that can be shared with other players who have a copy of the game, a PS3 console, and Internet connectivity. The construction of game levels can take place collaboratively (synchronously or asynchronously) or on an individual basis. A unique feature of the games in the LittleBigPlanet series is that, by playing them, users learn skills and concepts that can be used for the creation of new game levels. I selected this game series because of its accessible game design tools (creators do not need to be game designers or programmers), its colourful and humorous characters, and the sheer number of players, creators, and online 
contributors to the LittleBigPlanet community. As of March 2015, more than nine million game levels have been created and shared with the LittleBigPlanet series (http://lbp.me).

The sample for the study has been defined by time, rather than content, considering the threads/posts published in the first month of activity of the discussion forum in 2008, starting from the oldest thread. I then selected the same period of time for another year (2012) in order to consider the interactions that occurred after the release of the second, updated and expanded, version of the game (LittleBigPlanet 2 2011). I analysed the threads with a minimum of 10 replies (i.e. a minimum of 11 posts per thread), excluding threads with fewer or no replies, as well as threads with more than 20 replies (these threads are automatically moved to another section in the discussion forum). In order to collect, organise, and code the threads/posts retrieved from the discussion forum I used a computer assisted qualitative data analysis software (CAQDAS).

I analysed the threads/posts downloaded from the discussion forum looking into how participants cued, expressed, and used humour. From a discourse analysis perspective, I focused on the discursive functions of humour, analysing what humour was doing and how in the context of the interactions occurring in the online community of players and creators.

Data excerpts cited in this article are numbered sequentially in braces (e.g. $\{01\})$ and labelled as:

\{sequential number of the excerpt in the article\} [(unique number assigned to the thread)-yearmonth-day of the post-(position of the post in the thread/total number of posts in the thread)nickname of the user].

Shorter excerpts are presented in double quotations marks in parentheses. All quotes are cited verbatim, without corrections, as they appear in the discussion forum. In order to protect users' anonymity and confidentiality, their usernames have been substituted with second level nicknames.

\section{Findings and Discussion}

In this section I present and discuss the findings focusing on the major functions of humour identified in the study and how they contribute to shaping and structuring the interactions in the online community.

I analysed the corpus (826 posts) through three cycles of coding keeping detailed notes and research memos (Saldaña 2013). In the first cycle of coding I identified six main categories associated with uses and functions of humour. In the second and third cycle I refined and narrowed down the analysis of the functions of humour to three main themes. Of the 826 analysed posts, 377 (45.6\%) featured humour, for a total of 578 humorous occurrences. The main themes and categories identified in the analysis are (see Table 1): cushioning (downplaying and softening; 45.0\%), gluing (presenting, supporting, and amusing; 53.3\%), and disrupting (mocking; $1.7 \%$ ). 
Table 1. The functions of humour in the analysed posts.

\begin{tabular}{|c|c|c|c|c|}
\hline Function & Action & Definition & Occurrences & Percentage \\
\hline \multirow{2}{*}{$\begin{array}{l}\text { Cushioning } \\
(45.0 \%)\end{array}$} & Downplaying & $\begin{array}{l}\text { Diminishing one's own abilities, } \\
\text { achievements, and experiences } \\
\text { (Goddard 2006) }\end{array}$ & 161 & $27.9 \%$ \\
\hline & Softening & $\begin{array}{l}\text { Soothing critiques and feedback on } \\
\text { user-generated artefacts }\end{array}$ & 99 & $17.1 \%$ \\
\hline \multirow[t]{3}{*}{$\begin{array}{l}\text { Gluing } \\
(53.3 \%)\end{array}$} & Presenting & $\begin{array}{l}\text { Introducing one's own artefacts to } \\
\text { the community }\end{array}$ & 95 & $16.4 \%$ \\
\hline & Supporting & $\begin{array}{l}\text { Supporting and encouraging the } \\
\text { members of the community }\end{array}$ & 161 & $27.9 \%$ \\
\hline & Amusing & $\begin{array}{l}\text { Teasing (benevolently) and } \\
\text { prompting good humour }\end{array}$ & 52 & $9.0 \%$ \\
\hline $\begin{array}{l}\text { Disrupting } \\
(1.7 \%)\end{array}$ & Mocking & $\begin{array}{l}\text { Teasing (contemptuously) and } \\
\text { threatening other users' face } \\
\text { through sarcastic or impolite } \\
\text { remarks }\end{array}$ & 10 & $1.7 \%$ \\
\hline \multicolumn{3}{|l|}{ Total } & 578 & $100.0 \%$ \\
\hline
\end{tabular}

Data show an overall positive use of humour (in $98.3 \%$ of cases). Mocking humour appears in only 9 of the 826 analysed posts, for a total of 10 out of 578 occurrences of humour (1.7\%). In 2 of these 9 posts users make fun of a game level that is not easy on the eyes (e.g. "That looks really original but I can't have a proper opinion of it if it's featured in blur-ovision"). In another thread, 5 posts are dedicated to mocking the behaviour of a user who, in the opinion of some of the participants, is impolitely and insistently demanding help. In this context, users seem to employ humour to defend the unwritten rules of participation of the community. They do so by mocking the "deviant" behaviour of a user who makes peremptory requests for support (e.g. one participant writes: "Slave! Get me my slippers!").

In another thread a user performs the only observed act of flaming, which is "a hostile expression of strong emotions such as swearing, insults, and name-calling" (Lee 2005) by making fun of the religious beliefs of some players. In the last occurrence of disparaging humour, a participant sarcastically uses quotation marks to criticise poorly designed usergenerated game components ("It looks a lot better than a bunch of other 'tanks' I've seen"), but keeps the comment generic (by using "a bunch" and "other") without directing it at specific users. Besides these rare occurrences, the large majority of uses of humour shows a positive social function, which I will discuss in the following sections.

\subsection{Cushioning}

\subsubsection{Downplaying: Humour as a Discursive Veil of Ability and Effort}

Designing fun and captivating game levels is hard work and in several occurrences (27.9\%) participants use self-deprecating humour to veil statements related to their skills or the amount of effort necessary to complete their creations: 
$\{01\}$ [(22)-2008-11-11-(01/12)-Bartha]

Ampere Cave: Trials, my first published level.

Ok, so, after a good week or so of yelling at the editor every time something fell apart, I've

finally produced a level I'm happy with.

The full name is: "Ampere Cave: Trials Ver. 1.0"

By "yelling at the editor" the creator conveys passion, engagement, and dedication, discussing effort in a humorous way. This is also achieved through word selection, as the creator says "a good week" (not just "a week"), which underlines the time necessary to create the game level, and "every time" (not just "sometimes"), which emphasises a repeated and continuing effort. Further, the creator uses the words "finally" (which stresses difficulty and time) and "produced" (not just "made," which highlights the process and the final result). The construction "Ok, so," separates the first sentence from the rest of the post, creating anticipation and setting the stage for what follows. The use of the two commas further prolongs the "suspense" in a conversational way that draws on a writing tool (punctuation) to instantiate talk in typed form.

In another post, a creator (RepicO) presents a game level titled "Memorable Aura" and concludes the post with these words:

\{02\} [(48)-2012-10-30-(01/11)-RepicO]

This was again one of those projects where I pull out allmost all my hair and drink too much energy drinks.

This will be my last level for this year.

The creator conveys effort in a humorous way by saying "I pull out allmost all my hair and drink too much energy drinks," which is further reinforced by the use of the adverbs "again" and "too much." The adverb "allmost" can be interpreted as a functional element used to create a more "realistic" humorous representation, rather than diminish the expression of effort and engagement.

\subsubsection{Softening: Humour as a Buffer for Critiques and Peer-Feedback}

Receiving feedback is one of the main reasons why users present their game levels to the community. However, receiving harsh criticism may discourage them from designing new game levels or introducing them to the community. Further, many players-commenters are, or may become, creators, which potentially puts them "on both sides of the courtroom." In order to avoid disheartening creators and disrupting the overall positive and welcoming atmosphere in the discussion forum, participants strategically use humour to soothe their critiques when they provide feedback. The most common way of doing so is by complementing text with humorous abbreviations (such as "lol," i.e. "laughing out loud") and a variety of emoticons, like in the following conversation, in which users provide feedback to an extremely challenging game level presented in the opening post by Dory $(\{03\})$ :

$\{03\}$ [(44)-2008-11-24-(01/17)-Dory]

Run sackboy run

I've made a new level called RUN SACKBOY RUN

It's very difficult to finish but only lasts about $1 \mathrm{~min}$ 
I tried for a "just one more go" feeling to the level, and I think I pulled it off.

The level has you running at full speed the whole time and constantly in danger of being killed by moving electrified hazards.

You follow a yellow path and have to grab and push different objects (also yellow) and are constantly running and swinging and jumping all over the place.

So far I'm the only one too finish it and it is a race level so you can see who finished the level the fastest (so everyone else has 0 points at the moment lol)

I challenge some of you to finish it HAVE YOU GOT WHAT IT TAKESlol:)

$\{04\}$ [(44)-2008-11-24-(05/17)-Jamboss]

I played it, pretty original but JEBUS IT'S THE MOST FRUSTRATING LEVEL I'VE EVER PLAYED!!! :mad:

$\{05\}$ [(44)-2008-11-25-(06/17)-whatizwhat]

(Quotes previous post)

I agree 100\% Honestly, after the 5th try, I got to the 4th stage (part? lol idunno) and gave up.

Rated a 5/5 though. :)

$\{06\}$ [(44)-2008-11-25-(08/17)-984st]

I'm working on it ---

30th try here I come.

$\{07\}$ [(44)-2008-11-25-(09/17)-Dory]

lol keep on in there son:)

$\{08\}$ [(44)-2008-11-25-(10/17)-984st]

$* * * * * *$ it's impossible $><>$

I managed to escape the platform that crushes you down, but after I drop down the other one to the right kills me straight away -_-

$\{09\}[(44)-2008-11-25-(12 / 17)-984 s t]$

******** impossible D:

Awesome level though, I'm addicted xD

$\{10\}$ [(44)-2008-11-26-(14/17)-NBJ]

Thank you for creating the most punishing level ever imagined :) I have not cleared it yet but give me time lol.

Dory humorously challenges the community to beat a very difficult game level that she created $(\{03\})$. Those who accept the challenge end up expressing frustration, but they do so by using humour to mitigate their statements. They use humorous cues such as wordplay and capitalization ( $\{04\}$ "JEBUS" instead of "Jesus"), extreme case formulations (Pomerantz 1986; Edwards 2000), i.e. "extreme" terms such as all, none, or absolutely ( $\{04\}$ "THE MOST FRUSTRATING LEVEL I'VE EVER PLAYED!!!," $\{05\}$ "I agree 100\%," and $\{10\}$ "the most punishing level ever imagined"), asterisks replacing swear words ( $\{08\}$ and $\{09\})$, and sarcasm ( $\{06\}$ "30th try here I come" and $\{10\}$ "Thank you for creating the most punishing level ever imagined"). An extensive use of the "lol" acronym and emoticons sets a humorous tone for comments that might have otherwise been perceived as harsh or derogatory. 


\subsection{Gluing}

\subsubsection{Presenting: Humour as a Protective Disguise}

By presenting, playing, testing, sharing, and commenting on user generated game levels, participants create social and creative interactions that constitute the core of the discourse in the community. In this context, one of the emerging practices and literacies in creative online spaces is the ability to meaningfully sample and remix media content (Jenkins et al. 2009). This creative form of appropriation represents an active engagement with cultural materials and media. It allows participants to design content using common references (e.g. popular digital games or game characters) to express themselves and share their personal interpretations of cultural elements with an audience of peers who share the same interests (e.g. video games). This form of sampling, remixing, and reinterpreting engenders copyright issues and top-down forms of censorship. In order to avoid potential copyright infringements and the deletion of their game levels based on popular culture, participants use humour as a protective disguise of their creations, as discussed in the following example:

\{11\} [(13)-2008-11-06-(01/12)-Softjets]

MGS: Tactical espionage action

My newest project (currently on hiatus, due to potential copyright implications) was wondering if anyone wanted to try it out.

$\{12\}$ [(13)-2008-11-06-(02/12)-manna992]

im gonna go and play your level. i love mgs! im working on a song now from mgs

$\{13\}$ [(13)-2008-11-08-(06/12)-yryrden]

I'm thinking of doing something similar... but do it in a series of levels so it can be extra detailed and accurate. I doubt i'll publish it though, it may just get taken down lol.

$\{14\}$ [(13)-2008-11-08-(07/12)-bluep4ain]

Just a friendly reminder, but you do realize the level might get deleted off the servers, right? Or haven't you noticed all the Mario levels disappearing? Heck, even nautagus' God of War level...

Copyright reasons.

Still, I'll try it out if I can on the weekend. :)

\{15\} [(13)-2008-11-08-(08/12)-Softjets]

Only levels that have graphics from other games are being taken down ;P i'll be just fine.

$\{16\}$ [(13)-2008-12-07-(09/12)-ydready]

This is the best metal gear solid themed level ive played so far, hands down.

The title has changed though...smart move softjets haha. :)

$\{17\}$ [(13)-2008-12-07-(10/12)-KnblBlood]

I might give it a try, I love MGS but there are just to much MGS levels out there.

\{18\} [(13)-2008-12-07-(11/12)-Brilliant Wtrs]

Um...took me a while to find. Apparently the level is called "Getal Mear Tolid: Sactical Aspionsage Ection" 
Explain yourself.

EDIT: Oh yeah and the level was fairly good, definitely the best MGS so far. I also managed \#1 score: 4570

$\{19\}$ [(13)-2008-12-08-(12/12)-Mageda]

Quote:

Originally Posted by Brilliant Wtrs

"Getal Mear Tolid: Sactical Aspionsage Ection"

LOL. That's pretty funny.

I'll try to find and play it later on. :)

In this conversation participants discuss a game level titled "MGS: Tactical espionage action." "Metal Gear Solid" ("MGS"), "Mario" (which stands for "Super Mario Bros."), and "God of War" are popular digital game series. The creator of the game level inspired by "Metal Gear Solid" talks about "potential copyright implications" ( $\{11\})$, a concern picked up by other users in subsequent comments ( $\{13\}$ and $\{14\})$. The creator finds a humorous way to disguise the game level by coining new morphemes and blending parts of words (Dynel 2009) through a clever "letter-play" that "remixes" the first letters of the original title:

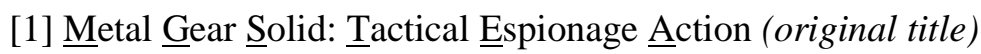

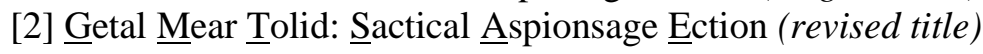

The sequence of the first letters changes from "MGSTEA" (in the original title) to "GMTSAE" (in the revised title), but all the letters are maintained. This technique prevents the administrators of the online platform from finding the game through a textual search. The remixed title becomes a situated identifier and an "inner joke" accessible only to the members of the community. Further, the adjective "Tactical" [1] has been skilfully transformed into "Sactical" [2], which refers to "Sackboy," the protagonist of LBP. Other examples of "sack-fied" titles of usergenerated game levels found in the analysed posts include "The Lost City Of Sacktopia" and "Trouble in Sackville!" (the "sack" element also appears in participants' nicknames). By "sackfying" names and adjectives, users situate their game levels into the LittleBigPlanet world in a creative and humorous way, combining humour and specialist (game-specific) language.

\subsubsection{Presenting: Humour as a Connector between the Virtual and the Real}

In some presentations, humour carries a "gluing" function that might not be immediately apparent: it works as a connector between the virtual world (LittleBigPlanet and user-generated game levels) and the real world (sleeping, thinking, and working). Let's consider the following excerpt:

\{20\} [(33)-2008-11-17-(05/14)-Thend1]

A daytime sequel is a major possibility! near the end I started thinking of making it a series, I will have to figure out something even bigger and better. I'm already loosing sleep thinking of my next creations lol. LBP makes work and sleep very difficult.

The last part of this comment can be transcribed as follows: 
[1] I'm already loosing sleep thinking of (real world)

[2] my next creations (virtual world)

[3] lol. (connects the real world and the virtual world)

[4] LBP (virtual world)

[5] makes work and sleep very difficult. (real world)

In this example, the humorous acronym "lol" [3] works as a connector between two alternate references to the real ([1] and [5]) and the virtual world ([2] and [4]).

This function of humour also appears in other instances, when players discuss the "real world" effects of the interactions in the virtual/game world, as illustrated by the following excerpt:

$\{21\}$ [(51)-2012-11-24-(05/15)-advncd]

Excellent level! Its not easy to master it and I really felt the burning sun at my skin while trying to stay alive :)

Very good job :)

In this excerpt the user makes a humorous statement that puts in a relationship the virtual experience of the game level with a real world sensation. The virtual experience and the real sensation are intertwined through humour, which functions as a connector between the two worlds:

[1] I really felt (real world)

[2] the burning sun (virtual world)

[3] at my skin (real world)

[4] while trying to stay alive (virtual world)

[5] :) (connects the real world and the virtual world)

The two interspersed planes, real ([1] and [3]) and virtual ([2] and [4]), are fused and harmonised through humour at the end of the sentence ([5]). Other users pick up this theme in subsequent posts discussing the connection between real world sensations and the virtual world of the game ( $\{22\}$ "Dont forget your suncream!" and $\{23\}$ "feel the sun"):

$\{22\}$ [(51)-2012-11-27-(06/15)-GGETh1]

Thanks everyone! I guessed it wouldn;t be everyone's cup of tea this one so i'm glad you liked it.

I've just updated and republished to try and smooth some lag out.

Dont forget your suncream!

$\{23\}[(51)-2012-12-02-(09 / 15)-$ scoovee $]$

OMG this was totally incredible. Wuuaau !!!! GGETh1 the atmosphere of the level is really awesome, feel the sun, was hard but the graphics was incredibly wonderfull. do you have my heart :D

In this example, the creator of the game level (GGETh1) followed up advncd's comment ( $\{21\})$ by saying "Dont forget your suncream!" ( $\{22\})$. Again, this humorous statement combines the virtual and the real, and carries at least three discursive functions: it acknowledges that humour has been recognised, it keeps the humorous conversation going, and it contributes to maintaining a positive atmosphere in the community. Further, this use of humour carries a very practical 
function (discussed in detail in the following section), as it contributes to attracting more players. In fact, the more a virtual game is perceived as real, the more it promises a realistic and enticing player experience.

\subsubsection{Presenting: Humour as a Strategic Tool to Attract Players}

In the second line of the post presented in the previous section $(\{22\})$, the creator of the game level (GGETh1) informs the audience that the game has been updated and improved. Right after that, she capitalises on the humorous statement of the other participant ( $\{21\}$ "I really felt the burning sun at my skin") and invites other users to play the game level by using humour herself ( $\{22\}$ "Dont forget your suncream!"). By building on a previous humorous statement, the creator tries to attract more players, which is one of the major goals and sought-after outcomes in the analysed community. In fact, the number of plays represents the status of a creator in the community and can influence productivity and motivation for further creative efforts, as exemplified by the following conversation:

$\{24\}$ [(45)-2012-10-26-(04/19)-Aphostrat]

Thanks for being the first play :) the review was very nice as well. Still struggling for views a bit but i can only hope word gets around for it! :D

$\{25\}$ [(45)-2012-10-26-(05/19)-punkin-p]

No problem. Level like this deserves a bigger audience!

\{26\} [(45)-2012-10-27-(06/19)-Aphostrat]

last play was 17 hours ago and it has had only 16 plays in total in 2 days... i dont expect a big audience now :(

$\{27\}$ [(45)-2012-10-27-(07/19)-scoovee]

Aphostrat I will play this level today I promise :D

$\{28\}$ [(45)-2012-10-27-(08/19)-kitzbitboi]

Just cued this :) can you try my latest level? scary planet

$\{29\}$ [(45)-2012-10-27-(09/19)-Mediacad1511]

16 plays in 2 days? That sucks man, it looks good so I'll queue it. :D

$\{30\}$ [(45)-2012-10-28-(10/19)-Aphostrat]

thanks everyone! i will get round to playing your level as well kitzbitboi asap!

\{31\} [(45)-2012-10-29-(13/19)-9roguebit]

man, I played this level yesterday and really liked it. The scenery was fantastic and the pacing was perfect, even in the mine cart area. There are a couple of tricky spots but that just made it all the more fun and satisfying when you finish the level. Outstanding job on this! Tweeted about it this morning so maybe that'll get you 2 more plays. :)

$\{32\}$ [(45)-2012-10-29-(14/19)-Aphostrat] 
thanks for trying to get the word out about it. The lack of plays on this has really knocked me back when it comes to my motivation to create anything else for lbp2. On my moon i have 4 projects nearing completion and yet i can't being myself to finish them because i'm constantly thinking about the disaster of a first week i have had with this one. I may stop lbp2 now and head over to lbp karting... maybe i can make a name for myself a bit more there? after all i work with $3 \mathrm{~d}$ programs almost everyday so i am pretty sure i can come up with something good on a $3 \mathrm{~d}$ editor!!

This sequence shows how much creators care about the number of plays their game levels receive, in order to "make a name" $(\{32\})$ for themselves in the community. Most participants seem to be aware of it and try to increase the number of plays to support skilled creators and promote meritorious game levels. Having a low number of plays can dishearten creators.

On the other hand, the popularity of a level can cheer them up and boost their confidence, as demonstrated by the following comment $(\{33\})$ posted by the creator of the game level, in the same thread, after almost a month from the post in which she was complaining about the low number of plays $(\{24\})$ :

\section{$\{33\}$ [(45)-2012-11-26-(18/19)-Aphostrat]}

Mahoosive bump but i bring great news!

This level has now not only been spotlighted by LBPC itself but the famous player Chimper from Missile Panther has made a video of this level! (and got a **** sweet score on it too! XD)

i have added it to the first post in the thread! If you have yet to decide if you want to play this level or not that video will make your decision for you! SO HAPPY! :D

In this post, the creator acknowledges the time elapsed between the two posts ("Mahoosive bump," i.e. a massive break between posts), but justifies it with the importance of the content to be disclosed ("but $\mathrm{i}$ bring great news"). Her enthusiasm is conveyed through several discursive features: she brings "great news" (not just "good news"), LBPC (which is the acronym of the name of the analysed discussion forum) "itself" spotlighted the game level (not another generic website), the player who made the video of the game is "famous" (not just a common player), and the score the game level received is "sweet" (not just positive). Six exclamation marks, two broad smiley/grin emoticons ("XD" and ":D" that represent a "bigger smile" than the classic smiley ":)" emoticon), the capitalisation of the last words of the post ("SO HAPPY"), and the syntactic construction "not only... but" (instead of a simple conjunction such as "and") further emphasise the enthusiasm of the author. The creator took advantage of this enthusiastic and smiling post to, again, invite new players by highlighting the positive feedback it received. An even more explicit invitation is presented before the end of the post ("If you have yet to decide if you want to play this level or not that video will make your decision for you!"). Overall, the analysis shows that participants care a lot about the popularity of their creations. In this context, they strategically use humour and "smiling posts" to invite new players in order to increase the visibility of their game levels and advance their status in the community.

\subsubsection{Supporting: Humour as an Instrument of Social Cohesion}

In one of the opening posts, a user conveys humour by inventing a title and a "cinematic" description to present the game level to the community: 
$\{34\}$ [(02)-2008-10-26-(01/14)-Mike]

When There's No Online

Never mess with a LBP player who's angry because there's no online yet.

(Link to YouTube Video)

This was my first level in the full LBP- it's kind of short and simple, but it's very challenging.

The topic of this game level pertains to LittleBigPlanet ("LBP"), its online community, and a real problem affecting all players (the game servers are offline). In this example, the humorous message is conveyed through different modes: the very creation of the level, the naming of the level ("When There's No Online"), and the cinematic description to introduce it ("Never mess with a LBP player who's angry because there's no online yet"). Through these humorous endeavours the creator of the game level conveys serious information "without appearing to do so" (Mulkay 1988: 69). The message is addressed to a twofold audience: the users in the online community, as a potential "allies" and amplifiers of the message, and the developers of the game, as final, albeit indirect receivers of the communication. In this instance, humour functions as a discursive instrument of protest deployed to call attention to a real world problem that affects all players, recruit supporters to amplify the message, and let the community's voice be heard. Other users pick up this theme (servers are down, there is no online access) in their replies to Mike's opening post $(\{34\})$ :

$\{35\}$ [(02)-2008-10-26-(06/14)-Dory]

Well done dude, and i like your pod. Very minimalistic :D

The servers don't really matter to me at the mo as i'm in the UK and we have to wait about another 10 days but $i$ would still like to see the servers up so there will be more vids of levels that players film because they like em :)

$\{36\}$ [(02)-2008-10-26-(08/14)-CPark]

Nice level, very cool.

Hopefully the online is up tomorrow, because I'd love to do some work on my beta levels. Maybe spruce them up with better materials.

$\{37\}$ [(02)-2008-10-27-(11/14)-Quizter]

Nice level Mike well done for a first attempt, will check it out when the servers are online.

Cheers Quizter

The fact that other users discussed the theme and the problem posed by Mike ( $\{34\})$ shows how humour can function as a social vehicle and a propeller of participation. Dory continued the discussion $(\{35\})$ the following day in another entry in another thread $(\{38\})$ :

$\{38\}$ [(03)-2008-10-27-(02/14)-Dory]

i haven't even got the game yet as i live in the scum of the earth ENGLAND:p

Well thats how sony have made me feel anywaygrr:mad::(

The two posts by Dory ( $\{35\}$ and $\{38\})$, published in two different threads in subsequent days, look like a dramatic crescendo "instigated" by Mike's original post $(\{34\})$. In the first thread ( $\{35\})$ Dory states: "i'm in the UK and we have to wait about another 10 days." In the second thread $(\{38\})$ the statement is made more specific through word selection and capitalisation 
("ENGLAND" instead of "UK") and reinforced through an extreme case formulation. In this case, the user takes her statement to extremes by defining the place where she lives (England) as "the scum of the earth" $(\{38\})$. This assertion is mitigated by the humorous "tongue out" emoticon (":p") at the end of the line, to emphasise the jocular and ultimately benevolent nature of the statement. Rather than an expression of sarcasm or "mock impoliteness" (Culpeper 1996; Bousfield 2008: 118), this comment sounds like an "impolite mock" with a shade of selfdenigrating humour (Zajdman 1995), since she is an inhabitant of England. The subsequent line in this post denotes a change in the register (cued by a new line and by the exclamation "Well"). In this line Dory elaborates her thoughts blaming the producer of the game ("sony") for this feeling and condition. She reinforces the statement through cues positioned at the end of the line (which is also the end of the sentence and of the post) expressing frustration (through the onomatopoeic interjection "grr"), anger (through the ":mad:" emoticon, which is replaced by a graphic symbol that depicts an angry face of the protagonist of LBP, Sackboy), and sadness (the ":(" emoticon).

Another example of humour conveyed through extreme case formulations is presented in a thread dedicated to a game level titled "Spider Cave." The creator of this game level (Softjets) and other participants (CPark, Gerva44, and Hara) discuss "arachnophobia":

\{39\} [(04)-2008-10-27-(01/16)-Softjets]

-My first level (which i'm showing off on my first post, Hi everybody). I'm a little proud of it, although i do realize it has many flaws. If you guys have some free time to look it up that would be cool, it's short and sweet. You won't regret it. It's titled spider cave exactly

$\{40\}$ [(04)-2008-10-29-(07/16)-CPark]

I hoped to at least make my way out of the cave, but it just ended randomly. Plus, the music didn't exactly match the atmosphere you were going for. Also, where were the spiders?

\{41\} [(04)-2008-10-29-(09/16)-Gerva44]

Sadly, I'm arachnaphobic so I'm sure the stage is awesome.

\{42\} [(04)-2008-10-29-(10/16)-Softjets]

it has surprisingly little to do with spiders :(

I may not scare you as much as I would like to...

(elided text in which the author discusses other features of the game)

The spiders, where simply stickers ( $\mathrm{i}$ was suppose to change them to real spiders at some point, but i got lazy :o and started a newer grander project (to be unveiled at a later date)

\{43\} [(04)-2008-10-29-(11/16)-Hara]

I'll have a look when I get my hands on the PS3 in a bit. I'm arachnophobic too so there's really not any real looking spiders is there?! I can handle seeing non-real ones! :p

$\{44\}$ [(04)-2008-10-29-(12/16)-Softjets]

(Quotes previous post)

Not really, just sticker ones... Unless flat sticker spiders invoke terror from the deepest pits of hell in you, you should be fine. :p

In LittleBigPlanet "stickers" are virtual decorations that can be applied on objects in any game level. The extreme case formulation "invoke terror from the deepest pits of hell in you" ( $\{44\})$ is used by the creator to reinforce the statement made in a previous comment ( $\{42\}$ "The spiders, 
where simply stickers") using a different register of humour in response to Hara's humorous statement ( $\{43\}$ "I can handle seeing non-real ones! :p"). This interaction reflects Edward's (2000) study on nonliteral and metaphoric uses of extreme case formulations that are used to achieve ironic, teasing, and humorous objectives. Edwards (2000: 372) argues:

ECFs are clearly not the only ways of signalling exaggeration, irony, humour, and so forth, and are likely to occur with other features of talk including specific lexical selections, contrasts with known facts, mocking intonation, deadpan delivery, various facial expressions (raised eyebrows, forced smiles), and so on.

In the last excerpt cited $(\{44\})$ one can observe the features of talk described by Edwards seamlessly at work to accomplish a series of discursive goals, such as restatement, sympathetic interaction, and constitutive laughter. In this example, all the features of talk enumerated by Edwards appear in the post: specific lexical selection ("invoke," "terror," and "pits of hell"), contrast with known facts ("flat sticker spiders"), mocking intonation (marked by the conjunction "unless"), deadpan delivery (cued by "Not really, just sticker ones..." and "you should be fine"), while the "facial expression" in this computer-mediated communication is rendered by an emoticon at the end of the sentence (": $p$ " which represents "sticking out a tongue"). Also of note is the use of the adjective "real" as a humorous tool of interpretation and negotiation of what is "real" in the real world (e.g. arachnophobia: $\{41\}$ "Sadly, I'm arachnaphobic" and $\{43\}$ "I'm arachnophobic too"), what is "real" in the virtual game world (e.g. arguably, three-dimensional moving spiders: $\{42\}$ "i was suppose to change them to real spiders at some point"), and what is "non-real" in the virtual game world (e.g. virtual spider stickers: $\{43\}$ "so there's really not any real looking spiders is there?! I can handle seeing nonreal ones! :p"), a topic discussed in one of the previous sections.

In another thread, a creator presents two game levels. One of them is called "Saved by the Light":

$\{45\}$ [(06)-2008-10-29-(01/16)-Mageda]

Saved by the Light

You're trapped in a dark cave Try to find a way out using the lights.

A participant comments:

\{46\} [(06)-2008-10-30-(09/16)-Softjets]

my character glows, so saved by the light shouldn't be to bad.

This comment is picked up by another user who says:

\{47\} [(06)-2008-10-30-(14/16)-Quizter]

Saved by the light was good but was just a bit too dark though Softjets went okay cause he had on his Devil Skin with glowing eyes :)

The analysis of this conversation shows that humorous posts in the discussion forum can function as "baits" for social interaction. In fact, besides eliciting humour, they can be interpreted as invitations to responses that keep a congruent convivial register and engender a sociable atmosphere. Further analysis suggests that humour can function as a two-way 
"discursive icebreaker": on one hand, users post humorous messages to attract comments; on the other hand, they look for such messages and use them as gateways to the conversation. In fact, it looks almost irresistible not to follow up a humorous statement with some kind of comment that keeps the conversation going, which contributes to creating a smiling and cohesive mood in the community. To summarise, participants use humour as an instrument of social cohesion to address real world issues (at times through humorous forms of protest), build on each other's posts using humour to attract responses or join the conversation, and maintain a pleasant atmosphere in the community.

\subsubsection{Amusing: Specialist Humour in Interaction}

Data show that in several occasions $(9.0 \%)$ participants share humorous posts just "for fun," to engender and maintain a smiling and non-judgmental atmosphere in the community. In the analysed posts, humour is tightly connected to specialist language, which is a variety of language that can be distinguished from everyday talk and that is used by distinct social groups in situated contexts (Halliday \& Matthiessen 2004; Woodward-Kron 2008; Hayes \& Lee 2012). For this study, on more than one occasion, it would have been impossible to grasp the humour conveyed by participants without a context-specific knowledge of LittleBigPlanet, its in-game humour and creative affordances, and the investigated online community as a whole. Specialist humour builds on what can be understood exclusively by the members of the community. It is part of an "insider's code" that needs to be deciphered in order to achieve a knowledgeable and legitimate participation. Further, by sharing, recognising, and perpetuating specialist humour, users establish unwritten rules of participation based on specialist knowledge that strengthen the cohesiveness of the community and define its identity by separating insiders from outsiders.

In the following excerpt, a user called Thunda comments $(\{48\})$ on a game level created by Mike (\{34\}):

\{48\} [(02)-2008-10-26-(02/14)-Thunda]

ACED - which wins you

Mike dozer lol

$=)$

good level short and sweet looked hard

The phrase "ACED - which wins you" is a direct quotation from LittleBigPlanet that appears at the end of each completed game level to inform the player about her success ("ACED") and the prizes that she will receive as a reward ("which wins you"). A humorous quotation is a direct citation from a pre-existing text that demonstrates the user's knowledge of such text (Dynel 2009) and the assumption of a shared knowledge with the audience. In this form of "staged intertextuality" (Kotthoff 2002) humour functions as a bonding element that harnesses the inclusive and exclusive affordances of specialist language that define the boundaries of the community (a joke that can be understood only by insiders). The prize elicited here is a "Mike dozer," which is a humorous neologism (Dynel 2009) that refers to the "Skulldozer," a mechanical creature that chases the protagonist of the game in a preset level of LittleBigPlanet. Humour is cued by the acronym "lol" and a smiley emoticon ("=)" which is a variation of the most common ":)" or ":-)"). Without the knowledge of this specific game level and the prize system in LBP (both expressed through specialist language) it would have been impossible to 
understand the hinted connection and grasp the humour conveyed by the creator in the game level and highlighted by the commenter in the post.

\section{Limitations and Recommendations for Future Research}

This study is limited by the fact that it is not possible to know the demographics of the participants, such as age, gender, or origin. In future studies, such information would provide important variables to better understand how humour is used across social groups and populations. The presence of some non-standard (and, at times, ungrammatical) language suggests that not all posters in the community are native speakers of English. Even if language issues never arose among participants in the analysed threads, it would be fascinating to conduct a comparative study on the uses of humour by native and non-native English speakers.

Throughout the analysis, in many circumstances it would have been impossible to trace, grasp, and interpret humour without a profound (specialist) knowledge of gaming, game design, and LittleBigPlanet, with its unique features, tools, and affordances. Tracy (2010: 843) argues:

Learning a culture's basic vocabulary and grammar skills is one thing, and understanding its tacit jokes and idioms is an entirely more difficult feat. Hidden assumptions and meanings guide individuals' actions whether or not participants explicitly say so.

In order to understand such "tacit jokes" and "hidden assumptions and meanings" researchers need to take a participatory stance, which echoes the need for a renewed methodological approach to online communities, enlightened by ethnographic insights (Androutsopoulos 2008; Lammers et al. 2012). In other words, researchers need to become insiders, not just observers, of highly situated (and often specialised) discourses in online environments. In this context, future research could explore the relationship between in-game humour and humour conveyed by users in online interactions, applying intertextual and multimodal approaches to discourse analysis that can provide further understandings of cues, uses, and functions of humour in computer-mediated contexts.

\section{Conclusions: Online Humour as Community-Building Cushioning Glue}

Considering the dearth of research on humour in $\mathrm{CMC}$, the purpose of this study was to analyse humour and its discursive functions in naturally occurring interactions in an online community in which participants present, discuss, and critique user-generated artefacts (digital game levels). Findings show that users express and cue humour through specific linguistic tools and techniques, such as lexical selection, capitalisation, wordplay, extreme case formulations, and emoticons, connecting conversational forms of humour with the specialist language of gaming, game design, and LittleBigPlanet.

Users create humorous titles and descriptions to achieve strategic discursive goals: to veil statements of ability and effort (downplaying), buffer critiques and peer feedback (softening), avoid copyright issues that may cause the deletion of their game levels, connect the virtual and 
the real, and attract players (presenting), encourage other participants (supporting), and spread an atmosphere of fun and enjoyment (amusing).

Without humour, users could perceive statements of ability and effort as signs of ostentation or self-pity. On the other hand, by encapsulating them in protective "humorous cocoons," participants are able to discuss them without showing conceit or self-pity, thus maximising the impact of their post and attracting more players. Effort is a highly valued element in the community and users tend to associate it with thorough and well-designed game levels that are worth to be played. In this context, humour offers creators the opportunity to discuss it without being perceived as self-indulgent "moaners" or "whiners."

The analysis shows that, in this community, more plays mean more popularity and more opportunities to improve as game designers through participants' feedback. In order to buffer criticism and maintain an amicable environment, participants use humorous abbreviations and emoticons as "un-serious-risers" that lessen unfavourable comments. In this case, humour incentivises feedback and peer-learning, making it safe to offer and receive critiques in a nonjudgemental and improvement-driven environment, which reflects the iterative process of design and game design. To receive feedback, users need to present their artefacts in enticing ways. To do so, they often use humour to attract players and keep their creations safe from censorship (game levels inspired by copyrighted materials are often removed from servers and made inaccessible to other players).

Humour is adopted as a two-way "discursive icebreaker" that facilitates participation: on one hand, users post humorous statements to attract comments; on the other hand, they look for such humorous statements to join the conversation. Further, by grounding humour on specialist language, users create "insider jokes" that can be understood and enjoyed only by the members of the community. This form of "specialist humour" contributes to a knowledgeable and legitimate participation that structures the identity and the uniqueness of the community.

In conclusion, findings show that humour functions as a pervasive instrument of cohesion between participants, as they discursively build reciprocal support through constitutive laughter (Hampes 1999; Hubler \& Bell 2003) by publishing sympathetic posts and spreading a pervasive social smile (Ziv 2010), which confirms the facilitative nature of humour in naturally occurring online interactions (Graham 1995). On the other hand, the overwhelmingly positive use of humour seems to challenge superiority theories of humour (Martineau 1972), at least in designdriven online environments.

In the analysed community, humour manifests itself as a discursively constructed agent that engenders supportive bonds, contributes to a sociable atmosphere, and strengthens the community as a whole. It spurs and sustains social, creative, and learning endeavours as an integrative component of computer-mediated communication. Far from being a mere conversational ornament, humour emerges as a dynamic "cushioning glue" that structures and nurtures the interactions in the community.

\section{References}

Androutsopoulos, J. (2008). 'Potentials and limitations of discourse-centered online ethnography'. Language@Internet 5 (2008), article 8. urn:nbn:de:0009-7-16100. URL: http://www.languageatinternet.org/articles/2008/1610 
Angen, M. J. (2000). 'Evaluating interpretive inquiry: Reviewing the validity debate and opening the dialogue'. Qualitative Health Research 10 (3), pp. 378-395.

Attardo, S. (2003). 'Introduction: The pragmatics of humour'. Journal of Pragmatics 35 (9), pp. 1287-1294.

Baxter, L. A. (1992). 'Forms and functions of intimate play in personal relationships'. Human Communication Research 18 (3), pp. 336-363.

Baym, N. K. (1995). 'The performance of humour in computer-mediated communication'. Journal of Computer-Mediated Communication 1 (2), p. 0.

Berger, A. A. (2013). 'Forty five ways to make 'em laugh'. Israeli Journal of Humor Research 1 (3), pp. 45-57.

Bousfield, D. (2008). Impoliteness in Interaction. Amsterdam: John Benjamins.

Boxer, D., \& Cortés-Conde, F. (1997). 'From bonding to biting: Conversational joking and identity display'. Journal of Pragmatics 27 (3), pp. 275-294.

Brown, P., \& Levinson, S. (1978). 'Universals in language usage: politeness phenomena', in Goody, E. N. (ed.), Questions and Politeness, Cambridge: Cambridge University Press, pp. 56-310.

Canary, D. J., Stafford, L., Hause, K. S., \& Wallace, L. A. (1993). 'An inductive analysis of relational maintenance strategies: Comparisons among lovers, relatives, friends, and others'. Communication Research Reports 10 (1), pp. 3-14.

Cann, A., Calhoun, L. G., \& Bank, J. S. (1997). 'On the role of humour appreciation in interpersonal attraction: It's no joking matter'. Humour: International Journal of Humour Research 10 (1), pp. 77-89.

Culpeper, J. (1996). 'Towards an anatomy of impoliteness'. Journal of Pragmatics 25 (3), pp. 349-367.

Danet, B. (2001). Cyberpl@y: Communicating Online. Oxford: Berg/Oxford International Publishers.

Dynel, M. (2009). 'Beyond a joke: Types of conversational humour'. Language and Linguistics Compass 3 (5), pp. 1284-1299.

Edwards, D. (2000). 'Extreme case formulations: Softeners, investment, and doing nonliteral'. Research on Language and Social Interaction 33 (4), pp. 347-373.

Ferrara, K., Brunner, H., \& Whittemore, G. (1991). 'Interactive written discourse as an emergent register'. Written Communication 8 (1), pp. 8-34.

Garcia, A. C., \& Jacobs, J. B. (1998). 'The interactional organisation of computer mediated communication in the college classroom'. Qualitative Sociology 21 (3), pp.299-317.

Garcia, A. C., \& Jacobs, J. B. (1999). 'The eyes of the beholder: Understanding the turn-taking system in quasi-synchronous computer-mediated communication'. Research on Language and Social Interaction 32 (4), pp. 337-367.

Garcia, A. C., Standlee, A. I., Bechkoff, J., \& Cui, Y. (2009). 'Ethnographic approaches to the internet and computer-mediated communication'. Journal of Contemporary Ethnography 38 (1), pp. 52-84.

Gee, J. P. (2010). An Introduction to Discourse Analysis: Theory and Method (3 ${ }^{\text {rd }}$ ed.). New York: Routledge.

Geertz, C. (1983). Local Knowledge. New York: Basic Books.

Goddard, C. (2006). "'Lift your game, Martina!": Deadpan jocular irony and the ethnopragmatics of Australian English', in Goddard, C. (ed.), Ethnopragmatics: Understanding Discourse in Cultural Context, Berlin: Mouton de Gruyter, pp. 65-97. 
Graham, E. E. (1995). 'The involvement of sense of humour in the development of social relationships'. Communication Reports 8 (2), pp. 158-169.

Halliday, M. A. K. \& Matthiessen, C. M. I. M. (2004). An Introduction to Functional Grammar $\left(3^{\text {rd }}\right.$ ed.). London: Hodder Arnold.

Hampes, W. P. (1999). 'The relationship between humour and trust'. Humour: International Journal of Humour Research 12 (3), pp. 253-259.

Hancock, J. T. (2004a). 'LOL: Humour online'. ACM Interactions 11 (5), pp. 57-58.

Hancock, J. T. (2004b). 'Verbal irony use in face-to-face and computer-mediated conversations'. Journal of Language and Social Psychology 23 (4), pp. 447-463.

Hayes, E. R. \& Lee, Y. N. (2012). 'Specialist language acquisition and trajectories of IT learning in a Sims fan site' in Hayes, E.R. \& Duncan, S.C. (eds.), Learning in Video Game Affinity Spaces, . New York: Peter Lang, pp. 186-211.

Herring, S. C. (ed.) (1996). Computer-Mediated Communication: Linguistic, Social and CrossCultural Perspectives. Amsterdam: John Benjamins.

Herring, S. C. (1999). 'Interactional coherence in CMC'. Journal of Computer-Mediated Communication 4 (4), p. 0.

Herring, S. C. (2001). 'Computer-mediated discourse', in Schiffrin, D., Tannen, D. \& Hamilton, H. (eds.), The Handbook of Discourse Analysis, Oxford: Blackwell, pp. 612-634.

Herring, S. C. (2004). 'Computer-mediated discourse analysis: An approach to researching online behaviour', in Barab, S.A., Kling, R. \& Gray, J.H. (eds.), Designing Virtual Communities in the Service of Learning, Cambridge: Cambridge University Press, pp. 338376.

Herring, S. C. (2013). 'Introduction to the pragmatics of computer-mediated communication', in Herring, S.C., Stein, D. \& Virtanen, T. (eds.), Handbook of Pragmatics of ComputerMediated Communication, Berlin: Mouton de Gruyter, pp. 3-31.

Hübler, M. T., \& Bell, D. C. (2003). 'Computer-mediated humour and ethos: Exploring threads of constitutive laughter in online communities'. Computers and Composition 20 (3), pp. 277294.

Jenkins, H., Purushotma, R., Weigel, M., Clinton, K., \& Robison, A. J. (2009). Confronting the Challenges of Participatory Culture: Media Education for the 21st Century. Cambridge, MA: MIT Press.

Kotthoff, H. (2002). 'Irony, quotation, and other forms of staged intertextuality. Double or contrastive perspectivation in discourse', in Graumann, K. \& Kallmeyer, W. (eds.), Perspective and Perspectivation in Discourse, Amsterdam: John Benjamins, pp. 201-229.

Kücklich, J. (2005). 'Precarious playbour: Modders and the digital games industry'. Fibreculture 5 (1). URL: http://five.fibreculturejournal.org/fcj-025-precarious-playbour-modders-and-thedigital-games-industry

Kurtzberg, T. R., Naquin, C. E., \& Belkin, L. Y. (2009). 'Humour as a relationship-building tool in online negotiations'. International Journal of Conflict Management 20 (4), pp. 377-397.

Lammers, J. C., Curwood, J. S., \& Magnifico, A. M. (2012). 'Toward an affinity space methodology: Considerations for literacy research'. English Teaching: Practice and Critique 11 (2), pp. 44-58.

Lee, H. (2005). 'Behavioural strategies for dealing with flaming in an online forum'. The Sociological Quarterly 46 (2), pp. 385-403.

Lefcourt, H. M. (2001). Humour: The Psychology of Living Buoyantly. Dordrecht: Kluwer Academic Publishers. 
Long, D. L., \& Graesser, A. C. (1988). 'Wit and humour in discourse processing'. Discourse Processes 11 (1), pp. 35-60.

Martin, R. A. (1998). 'Approaches to the sense of humour: A historical review', in. Ruch, W. (ed.), The Sense of Humour: Explorations of a Personality Characteristic, Berlin: Mouton de Gruyter, pp. 15-60.

Martin, R. A. (2007). The Psychology of Humour: An Integrative Approach. Burlington, MA: Academic Press.

Martineau, W. H. (1972). 'A model of the social functions of humour', in Goldstein, J.H., \& McGhee, P.E. (eds.), The Psychology of Humour: Theoretical Perspectives and Empirical Issues, New York: Academic Press, pp. 101-125.

Mazur, J. (2004). 'Conversation analysis for educational technologists: Theoretical and methodological issues for researching the structures, processes and meaning of on-line talk', in Jonassen, D.H. (ed.), Handbook for Research in Educational Communications and Technology (2 ${ }^{\text {nd }}$ ed.), Mahwah, NJ: Lawrence Erlbaum Associates, pp. 1073-1098.

Mulkay, M. (1988). On Humour: Its Nature and its Place in Modern Society. Cambridge: Polity Press.

Norrick, N. R. (2003). 'Issues in conversational joking'. Journal of Pragmatics 35 (9), pp. 13331359.

Norrick, N. R. (2010). 'Humour in interaction'. Language and Linguistics Compass 4 (4), pp. 232-244.

Norrick, N. R., \& Chiaro, D. (eds.) (2009). Humour in Interaction. Amsterdam: John Benjamins.

Pennington, N., \& Hall, J. A. (2014). 'An analysis of humour orientation on Facebook: A lens model approach'. Humour: International Journal of Humour Research 27 (1), pp. 1-21.

Peräkylä, A. (2005). 'Analysing talk and text', in Denzin, N.K. \& Lincoln, Y.S. (eds.), The Sage Handbook of Qualitative Research ( $3^{\text {rd }}$ ed.), Thousand Oaks, CA: Sage, pp. 695-727.

Pomerantz, A. (1986). 'Extreme case formulations: A way of legitimising claims'. Human Studies 9 (2/3), pp. 219-229.

Saldaña, J. (2013). The Coding Manual for Qualitative Researchers (2 ${ }^{\text {nd }}$ ed.). Thousand Oaks, CA: Sage.

Shifman, L. (2007). 'Humour in the age of digital reproduction: Continuity and change in internet-based comic texts'. International Journal of Communication 1, pp. 187-209. URL: http://ijoc.org/index.php/ijoc/article/view/11/34

Smart, G. (2012). 'Discourse-oriented ethnography', in Gee, J.P. \& Handford, M. (eds.), Handbook of Discourse Analysis, New York: Routledge, pp. 147-159.

Sotamaa, O. (2007). 'Let me take you to the movies: Productive players, commodification and transformative play'. Convergence: The International Journal of Research into New Media Technologies 13 (4), pp. 383-401.

Starks, H., \& Brown Trinidad, S. (2007). 'Choose your method: A comparison of phenomenology, discourse analysis, and grounded theory'. Qualitative Health Research 17 (10), pp. 1372-1380.

Tannen, D. (1984). Conversational Style: Analysing Talk among Friends. Norwood, NJ: Ablex Publishing Corporation.

Thurlow, C., Lengel, L., \& Tomic, A. (2004). Computer Mediated Communication: Social Interaction and the Internet. London: Sage

Thurlow, C., \& Mroczek, K. (eds.) (2011). Digital Discourse: Language in the New Media. New York: Oxford University Press. 
Tracy, S. J. (2010). 'Qualitative quality: Eight "big-tent" criteria for excellent qualitative research'. Qualitative Inquiry 16 (10), pp. 837-851.

Vandergriff, I., \& Fuchs, C. (2012). 'Humour support in synchronous computer-mediated classroom discussions'. Humour: International Journal of Humour Research 25 (4), pp. 437458.

Wood, L. A., \& Kroger. R. O. (2000). Doing Discourse Analysis: Methods for Studying Action in Talk and Text. Thousand Oaks, CA: Sage.

Woodward-Kron, R. (2008). 'More than just jargon - The nature and role of specialist language in learning disciplinary knowledge'. Journal of English for Academic Purposes 7 (4), pp. 234249.

Wyer, R. S., \& Collins, J. (1992). 'A theory of humour elicitation'. Psychological Review 99 (4), pp. 663-688.

Zajdman, A. (1995). 'Humorous face-threatening acts: Humour as strategy'. Journal of Pragmatics 23 (3), pp. 325-339.

Ziv, A. (2010). 'The social function of humour in interpersonal relationships'. Society 47 (1), pp. 11-18. 